\author{
Associate Professor Süleyman BOLAT, PhD \\ E-mail: bolatsuleyman80@gmail.com \\ Department of Public Finance \\ Aksaray University \\ Assistant Professor Murat BELKE, PhD \\ E-mail: muratbelke@gmail.com \\ Department of Economics \\ Burdur Mehmet Akif Ersoy University \\ Professor Tolga OMAY, PhD \\ Email: omay.tolga@gmail.com \\ Department of Economics \\ Atilim University
}

\title{
HYSTERESIS HYPOTHESIS VS. STRUCTURALIST VIEW IN CANADA: A NEW TEST FOR THE SHARP BREAK AND SMOOTH SHIFT
}

\begin{abstract}
We have investigated the hysteresis hypothesis using a newly proposed unit root test which considers both sharp breaks and smooth shifts in its testing process for Canada during the period 1960-2019 in this study. The so-called unit root test allows researchers control for sharp breaks such as crises, smooth shifts such as nonlinearities, simultaneously. In proposing this highly complex trend structure, we are also proposing a new way for the macroeconomic theorist to model the unemployment rate following the structuralist view. It takes into account the structural breaks and possible nonlinearities as form of smooth shifts which leads to a new form of structuralist view. The empirical results display that the unemployment rates in Canada follow a non-hysteresis path under the presence of sharp and smooth structural breaks break.

Keywords: Unemployment, hysteresis, unit root test, sharp and smooth
\end{abstract}

JEL Classification : C12, C22, E24, J64

\section{Introduction}

The main point of most discussions on the dynamics of the unemployment process is finding out whether this process is stationary or subject to hysteresis. The temporary or permanent effects of the shocks caused by the economic crises or

DOI: $10.24818 / 18423264 / 55.2 .21 .06$ 
global recessions on the unemployment process form the basis of the issues discussed. In literature there are three main proposals to clarify the dynamic characteristics of unemployment rates. The first is the natural rate hypothesis, as proposed by Phelps (1967) and Friedman (1968), which predicts that the effects of economic shocks on the unemployment percentages are temporary. Also, they concluded the short-term fluctuations in unemployment rate will disappear in the long term. The second approach is the unemployment hysteresis hypothesis suggested by Blanchard and Summers (1986). As opposed to the natural rate hypothesis, they found that temporary shocks have permanent effects on unemployment rates, preventing the return of the unemployment rate to a natural cycle. The hysteresis hypothesis suggested that the cyclical fluctuations in an economy have more persistent impacts on the unemployment rate. Theoretical studies show that the permanent effects of shock on unemployment rates may be caused by several factors. The unemployment rates could be presented by the nonstationary process under this hypothesis. They include the insider-outsider model, loss of talent in workers, the decrease in the level of human capital, stigma effect, strong unions, worker protection laws and excessively high real wages. The third approach is the structuralist theory proposed by Phelps (1994), who assumes that most unemployment-related shocks are temporary, but unemployment rates can be permanently affected by structural changes in the economy in rare instances. These structural shifts can occur due to changes in labour productivity, technological change, real exchange rates, real interest rates, or energy prices.

The unemployment hysteresis hypothesis is critical for empirical researchers. With the development of the hypothesis, extensive literature has been created since the 1980s. Blanchard and Summers (1986) accepted the hysteresis hypothesis in their first study using DF (Dickey-Fuller) and ADF (Augmented Dickey-Fuller) unit root tests. Brunello (1990) and Mitchell (1993) where traditional ADF tests are examined. They reached conclusions confirming the effect of hysteresis in their studies. When the data ranges used in the analysis are insufficient, the powers of some traditional tests are also powerless. The results indicated that unemployment rate is stationary and were obtained in non-linear panel studies, which recently also included structural breaks (Christopoulos and Leon-Ledesma, 2007). Example of studies concluding the presence of hysteresis effect used by the non-linear unit root test methods are Leon-Ledesma and McAdam (2004) and Lee (2010).

There are many studies examining the temporary or permanent effects of shock in the series with unit root tests applied to the unemployment series. The stationary process was pioneered by Nelson and Plosser (1982). In addition, Perron (1989) demonstrated that shocks will have a temporary effect if structural breaks are taken into account in standard unit root tests. However, structural breaks characterized by a sharp transition, structural breaks, numbers and dates that are the precursors in the model and breaks are modeled using dummy variables in this study. The dummy variable approaches have a unique structure which can capture

DOI: $10.24818 / 18423264 / 55.2 .21 .06$ 
Hysteresis Hypothesis vs. Structuralist View in Canada: A New Test for the Sharp Break and Smooth Shift

the low frequency by using sharp transition, however, it can be smooth moderate or slow. Therefore, it can lead to a model misspecification problem. Trying to alleviate these problems regarding the form and number of structural breaks, Becker et al. (2006), Enders and Lee (2012 a, b), and Omay (2015) developed stationarity and unit root tests, respectively. This type of modeling can capture various type of structural shifts and nonlinearities as it is independent of structural forms (Enders and Lee, 2012a).

This paper provides a net contribution to Canadian literature for unemployment in different ways. First, we used the data covered an unusually long period of over 60 years for measuring unemployment to examine the unit root process or stationary using various type of test for Canada. Second, this is the first time to test the unemployment in Canada by using a SOR test, combining sharp structural break and smooth shifts. It may solve the possible misspecification problems of testing stochastic features of Canadian unemployment series in a long span data. Therefore, we may ensure the correct data generation process which can be used to inform correct economic policies. Third, this study departs from the literature by using unit root test with sharp structural break and smooth shifts over a long-time span data. The research of this suggests that simple numerical advantage helps the detection of both sharp and gradual transitions. Fourth, we generate a model based on sharp-hard breaks endogenously in contrast with the standard dummy variable unit root tests that is employed by exogenous determination. Thus, it also provides flexible options to analyze structure.

Why do we need to test Canada's unemployment in this paper? Canada is the world's eighth-biggest economy. It is the second-largest exporter of natural gas and sits on the largest pool of oil reserves outside the Middle East. Canada is largely a resource economy and its economy dominated by the booming oil and natural-gas sectors. Canada is highly exposed to the American economy, because so much of its trade is with the United States. We take a look at the big picture of what is actually happening with Canada about the unemployment process. We have used to test whether Canada's unemployment series is a unit root process or stationary using various type of test because of this.

Let's glance at Canada's economy and unemployment rates over the period 1960-2019. Canada's real GDP growth slowed sharply and inequality increased and the distribution of wealth became more skewed during the 1960s and 1970s. At that time, the unemployment rate increased so much and the economic turbulence of the 1970s raised the industries. The rise in Canada's employment was far more rapid than US during the 1970s and 1980s. But the unemployment rate started to increase during the 1990s. This had to lead economic instability and economic deterioration. In the whole post-war period, Canada was stuck in its worst recession during the 1980s and 1990s. Canada's economy almost certainly performed better than the previous one since 2000. It started to expand and upgrade its refineries and build new ones before the global financial crisis. Overall GDP growth was strong 
thanks to the resource boom and improved economic management during the 20002016 period in Canada (Riddell, 2018).

The structure of paper is as follows. Section 2 overviews the data and methodology of the paper and section 3 presents the empirical results and finally we display our conclusions in section 4 .

\section{Data and Methodology}

The variables used in the empirical study regarding the Canadian economy are derived from the Federal Reserve Bank of St. Louis (FRED) database. The analysis period was chosen according to the availability of the data, the period from January 1960 to June 2019. In the study, SOR unit root test is the test method for capturing different dynamics in the form of soft and sharp structural breaks, statedependent nonlinearity, or a mixture of these. The SOR test focuses only on the selection of the appropriate frequency, without the need for a prior knowledge of the dates, numbers, or pattern of breaks. The test allows the detection of both sharp and gradual transitions that performed exceptionally well in the modelling. The SOR unit root test allows intrinsic modeling of sharp-hard breaks, as opposed to standard dummy variable unit root tests, which allow only the external determination of breaks.

The method does not assume breakage in the case that there are no hard or soft structural breaks in the series (when the Fourier function parameter is not significant). Therefore, it allows a more flexible test structure. In addition, the testing process maintains its effectiveness in other situations, namely statedependent nonlinearity, smooth shifts and linear data generation, except for sharp structural breaks. The ST-TAR test, on the other hand, involves a very limited type of situation-dependent nonlinearity with smooth structural breaks.

In the study, where hard breaks were modeled using dummy variables, soft breaks were modeled using Fourier transform. However, the external determination of hard structural breaks in the study needs another procedure or a visual inspection to control the power of the test. In addition, the use of dummy variables creates more discontinuity in usage of de-trending data or nonlinear trend. In the case of an increasing number of Fourier transforms (cumulative) to capture sharp and smooth transitions in the series, the newly added Fourier function causes over-fit and overfiltration problems especially in the stochastic part of the series (Becker et al., 2006; Enders and Lee, 2012 a, b).

Shahbaz, Omay and Roubaud (2019) have proposed an extremely flexible testing process that solves these problems in two stages. The data generation process $\bar{y}_{t}, t=1,2, \ldots, 7$ is in a changing trend function to ensure with a smooth transition over the time domain. 
Hysteresis Hypothesis vs. Structuralist View in Canada: A New Test for the Sharp Break and Smooth Shift

Model A:

Model B:

Model C:

$$
\begin{gathered}
\overline{y_{t}=\alpha_{1}+\alpha_{2} F_{t}(\gamma, \tau)+\varepsilon_{t}} \\
y_{t}=\alpha_{1}+\beta_{1} t+\alpha_{2} F_{t}(\gamma, \tau)+\varepsilon_{i} \\
y_{t}=\alpha_{1}+\beta_{1} t+\alpha_{2} F_{t}(\gamma, \tau)+\beta_{2} F_{t}(\gamma, \tau) t+\varepsilon_{i}
\end{gathered}
$$

They proposed a test process that calculated in two steps following Shahbaz, Omay and Roubaud (2019) which agrees with Leybourne, Newbold and Vougas (1998). In the first step, only the deterministic component of the preferred model is estimated and the residues of the model are calculated using the genetic algorithm in a limited nonlinear optimization problem.

$$
\begin{array}{lc}
\text { Model A: } & \hat{\varepsilon}_{t}=y_{t}-\hat{\alpha}_{1}-\hat{\alpha}_{2} F_{t}(\hat{\gamma}, \hat{\tau}) \\
\text { Model B: } & \hat{\varepsilon}_{t}=y_{t}-\hat{\alpha}_{1}-\hat{\beta}_{1} t-\hat{\alpha}_{7} F_{t}(\hat{\gamma}, \hat{\tau}) \\
\text { Model C: } & \hat{\varepsilon}_{t}=y_{t}-\hat{\alpha}_{1}-\hat{\beta}_{1} t-\hat{\alpha}_{7} F_{t}(\hat{\gamma}, \hat{\tau})-\hat{\beta}_{7} F_{t}(\hat{\gamma}, \hat{\tau}) t
\end{array}
$$

In the second step, Enders and Lee (2012 a,b) calculated t statistics that are about $\widehat{\phi}$ in the ordinary least squares regression and it is below as:

$$
\hat{\varepsilon}_{t}=d(t)+\phi_{1} \hat{\varepsilon}_{t-1}+v_{t}
$$

$\bar{v}_{t}$ is a stationary disturbance term with a constant variance with $\bar{\sigma}^{2} \cdot d(t)$ is the deterministic function of t. In the case where $d(t)$ is known, the equation (7) can be directly estimated to test the absence hypothesis that displays the existence of a unit root $\left(\phi_{1}=1\right)$. If the form of $d(t)$ is unknown, any test for $\overline{\phi_{1}=1}$ is a problematic test. The SOR unit root test is based on the fact that $d(t)$ can be estimated approximately using the Fourier expansion.

$$
d(t)=\alpha_{0}+\sum_{k=1}^{n} \alpha_{k} \sin \left(\frac{2 \pi k t}{T}\right)+\sum_{k=1}^{n} \beta_{k} \cos \left(\frac{2 \pi k t}{T}\right), \quad n \leq T / 2
$$

$\mathrm{n}$ displays the cumulative frequency number in the Fourier expansion, $\mathrm{k}$ shows a specific frequency, and $\mathrm{T}$ determines the number of observations. The presence of numerous frequency components reduces the degree of freedom and leads to the problem of over-fitting. A Fourier approach that uses a low number of frequency components can often capture soft breaks in an unknown functional form. $\mathrm{n}$ also must be small enough to allow the evolution of the nonlinear trend to be gradual, because the strength of the test decreases as it increases (Shahbaz, Omay and Roubaud, 2019). Finally, test equation is as follows:

$$
\Delta \hat{\varepsilon}_{t}=\alpha_{0}+\sum_{k=1}^{n} \alpha_{k} \sin \left(\frac{2 \pi k t}{T}\right)+\sum_{k=1}^{n} \beta_{k} \cos \left(\frac{2 \pi k t}{T}\right)+\phi_{1} \hat{\varepsilon}_{t-1}+\sum_{i=1}^{p} \varphi_{k} \Delta \hat{\varepsilon}_{t-i}+v_{t}
$$

DOI: 10.24818/18423264/55.2.21.06 
It is a common practice to extend the lagged values of the dependent variable to consider any static dynamic in $\hat{\varepsilon}_{t}$ in testing equality. According to SOR unit root test, it is based on the model A, B, and C with Fourier transform and the hypotheses are below.

$\mathrm{H}_{0}$ : Unit root (Non-linear stationary-linear nonstationary)

$\mathrm{H}_{1}$ : Nonlinear stationary (Nonlinear and Stationary around simultaneously changing sharp and smooth trend)

\section{Empirical Results}

In this part we have used Canadian unemployment data to investigate whether the series is a unit root process or stationary using various type of test. Our first consideration is to test the unemployment series with traditional unit root test such as ADF then we consider the state dependent nonlinearity by using Kapetanios, Shin and Snell (2003) (Henceforth, KSS), and Enders and Granger (1998) (Henceforth EG) tests. Both of the testing structures are insufficient to capture correct structure of this long span data. We have used the time varying nonlinearities in the form structural break in the third stage. For this purpose, we have used Omay (2015) (Henceforth, FFFFF), Leybourne, Newbold and Vougas (1998) (henceforth, LNV) and Enders and Lee (2012b) FADF or EL test. These tests are not also sufficient to capture dynamics of the unemployment series of the Canadian unemployment series. There are various types of hybrid test which are involving state dependent and time varying nonlinearity, simultaneously in the recent unit root literature. By using these complex dynamics, we try to better describe the data generating process (DGP).

Although Omay and Yildirim (2014) (henceforth, OY LNV KSS), Christopulos and Lean Ledesma (2010) (henceforth, CL FKSS), Sollis (2004) (henceforth, LNV EG), Omay, Emirmahmutoglu and Hasanov (2018) (henceforth, OEH $a$ and $b$, LNV-AESTAR, FAESTR) have sufficiently advance structure to cover various type of dynamics, they are not managed to capture the actual dynamics of the Canadian unemployment series ${ }^{1}$. Finally, we have used the SOR test to detect the stochastic feature of the series under consideration. The findings of SOR test Model C is tabulated with respect to OY test and OEH ( $\mathrm{a}$ and $\mathrm{b}$ ) in order to make a better comparison of rival tests. The test results are follows:

Table 1. Unit Root Test Results Allowing the State Dependent and Time Varying Nonlinearity for Canada

\begin{tabular}{ccccc}
\hline & LNV & LNV_KSS (OY test) & LNV-AESTAR OEH test & SOR test \\
\hline Tests & -3.586 & -3.855 & 7.605 & $-5.236^{* * * *}$ \\
\hline
\end{tabular}

${ }^{1}$ The unit root test results of the tests are available upon request. 
Hysteresis Hypothesis vs. Structuralist View in Canada: A New Test for the Sharp Break and Smooth Shift

Note: The test results are obtained by using different criteria's such as AIC, SIC and the residual autocorrelation. The tabulated values for the test are the one with the best results obtained. Model $\mathrm{C}$ of the all tests.

The tabulated values for the tests are the ones with the best results obtained from these three criteria. Therefore, with any criteria the rival tests are not manage to represent a better performance than SOR test. The result of the SOR unit root test displays that the null hypothesis of a unit root is rejected. According to these empirical results, we assume that the unemployment rates in Canada follow a nonhysteresis path.

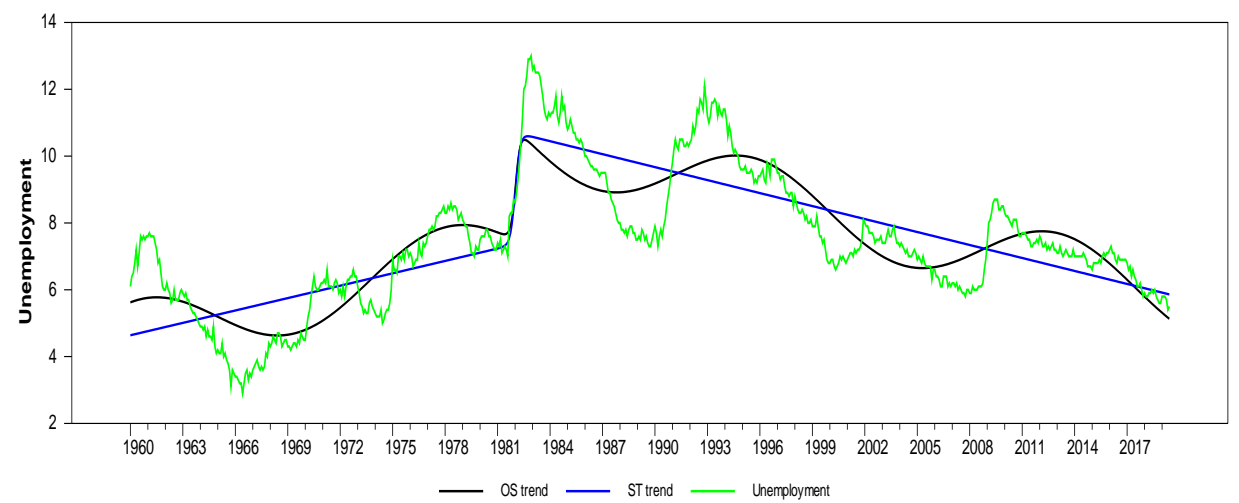

Figure 1. Nonlinear trends of LNV and SOR test with originals series for Canada

In figure 1, the blue trend is the LNV trend which is obtained by the Logistic function. The black one is the SOR test trend which is obtained by logistic plus a Fourier function. As it can be seen, the figure shows that the Fourier function perfectly captures the cyclical behaviour of the series. In addition to this, the logistic function well estimates the sharp structural break in 1981. The series has an increasing trend until 1981, after this point the long run trend of the unemployment series become negative. The logistic function is captured the sharp structural break and the long run behaviours of the series.

On the other hand, as we have mentioned above the Fourier function well explained the short run cycles or shifts. These cycles can also be modelled by exponential smooth transition. Nevertheless, the very similar tests OY and OEH tests which are using ESTAR and AESTAR function in their modelling startegy can not capture this cycle as we have tabulated the insignificant values of test in Table 1.

DOI: $10.24818 / 18423264 / 55.2 .21 .06$ 
This study departs from Koustas and Velos (1996)'s study in which their result have a persistence of shocks in the rate of unemployment in Canada. They found a permanent effect on the Canada unemployment rate during the 1960s and 1980s. The results from our study are compared to the study by Lin, Kuo and Yuan (2008) based on analysis can be employed in a nonlinear stationary for Canada. Their study conclude that their findings are compatible with our findings and their results support the idea that the existence of nonlinear stationary for Canada. They are in favor of the natural rate hypothesis that denote the dynamic behaviour of unemployment rate to return to a natural level in the long run. Similary, Chang (2011)'s study confirm that Canada's unemployment rate is a stationary process using the test with a Fourier function. The results are also largely consistent with our results in this study.

\section{Conclusions}

In this paper we presented a flexible unit root test, SOR, that capture about different dynamics in the form of soft and sharp structural breaks, state-dependent nonlinearity. With this method, it's crucial to understand that allows the detection of both sharp and gradual transitions in the modelling. The unknown form of the unemployment series of Canadian unemployment rate is investigated by using different unit root tests such as linear, state dependent nonlinear, time varying nonlinear and the hybrid which is considering state dependent, time varying nonlinearity simultaneously. Therefore, we can safely claim that the series under consideration have a sharp break in 1981. The long-run behaviour of the series is increasing before this point and decreasing after this point. Moreover, the Fourier function well captured the cyclical behaviour of the Canadian unemployment series.

The study asserts that the SOR test dynamics is the best way to find the perfect solution to the Canadian unemployment series. Our results provide strong support for the null hypothesis of a unit root is rejected in Canada. These empirical results assume that the unemployment rates in Canada follow a non-hysteresis path, they will return to the mean. This process of determining stationary points return to the mean without government intervention whatsoever in the labour market. Being able to withstand short-term shocks in the labour market is essential but at the same time it is important to be able take advantage of opportunities to the economy.

Flexible labour markets allow economies to cope with any shocks more effectively. Especially during the flexible labour practices, deregulated labour markets have boosted productivity and made the economy better able to adjust to shocks. Of course, labour markets need no government intervention to act a good policy and in the absence of any intervention by the government, unemployment process can come down and equilibrium.

Nowadays, the pandemic of Covid-19 may change the long-run direction of the unemployment series which is also be captured by logistic function. So first we are expecting a long run increase in the trend of unemployment. Then, most 
Hysteresis Hypothesis vs. Structuralist View in Canada: A New Test for the Sharp Break and Smooth Shift

probably the Fourier function may show an increase in the short run cycle. Therefore, the policy authority may benefit from this analysis and policy makers try to forecast future of long run unemployment and the cycles of Canadian unemployment rates.

\section{REFERENCES}

[1] Becker, R., Enders, W., Lee, J. (2006), A Stationarity Test in the Presence of an Unknown Number of Smooth Breaks. Journal of Time Series Analysis, 27(3):

381-409;

[2] Blanchard, O., Summers, L. (1986), Hysteresis and the European

Unemployment. NBER, Macroeconomics Annual, 1: 15-90;

[3] Brunello, G. (1990), Hysteresis and the 'Japanese Unemployment Problem':

A Preliminary Investigation. Oxford Economic Papers, 42(3): 483-500;

[4] Chang, T. (2011), Hysteresis in Unemployment for 17 OECD Countries:

Stationary Test with a Fourier Function. Economic Modelling, 28(5): 2208-2214;

[5] Christopoulos, D.K., Leon-Ledesma, M.A. (2007), Unemployment

Hysteresis in EU Countries: What do We Really Know about it?, Journal of

Economic Studies, 34(2): 80-89;

[6] Christopoulos, D., Leon-Ledesma, M.A. (2010), Current Account

Sustainability in the US: What did We Really Know about it? Journal of

International Money and Finance 29(3): 442-459;

[7] Enders, W., Granger, C.W.G. (1998), Unit Root Tests and Asymmetric

Adjustment with and Example using the Term Structure of Interest Rates.

Journal of Business \& Economic Statistics, 16(3): 304-311;

[8] Enders, W., Lee, J. (2012a), A Unit Root Test using a Fourier Series to

Approximate Smooth Breaks. Oxford Bulletin of Economics and Statistics, 74(4): 574-599;

[9] Enders, W., Lee, J. (2012b), The Flexible Fourier Form and Dickey-Fuller

Type Unit Root Tests. Economics Letters, 117(1): 196-199;

[10] Friedman, M. (1968), The Role of Monetary Policy, American Economic

Review, 58(1): 1-17;

[11] Kapetanios, G., Shin, Y., Snell, A. (2003), Testing for a Unit Root in the

Nonlinear STAR Framework. Journal of Econometrics, 112(2): 359-379;

[12] Koustas, Z., Veloce, W. (1996), Unemployment Hysteresis in Canada: an

Approach based on Long-Memory Time Series Models. Applied Economics, 28(7): 823-831;

[13] Lee, C.F. (2010), Testing for Unemployment Hysteresis in Nonlinear

Heterogeneous Panels: International Evidence. Economic Modelling, 27(5):

1097-1102;

DOI: 10.24818/18423264/55.2.21.06 
[14] Leon-Ledesma, M., Mcadam, P. (2004), Unemployment Hysteresis and Transition. Scottish Journal of Political Economy, 51(3): 377-401;

[15] Lin, C.H., Kuo, N-F., Yuan, C-D. (2008), Nonlinear vs. Nonstationary of Hysteresis in Unemployment: Evidence from OECD Economies. Applied Economics Letters, 15(11): 905-909;

[16] Leybourne, S., Newbold, P., Vougas, D. (1998), Unit Roots and Smooth Transitions. Journal of Time Series Analysis, 19(1): 83-97;

[17] Mitchell, W.F. (1993), Testing for Unit Roots and Persistence in OECD Unemployment Rates. Applied Economics, 25(12): 1489-1501;

[18] Nelson, C.R., Plosser, C.I. (1982), Trends and Random Walks in Macroeconomic Time Series Some Evidence and Implications. Journal of Monetary Economics, 10(2): 139-162;

[19] Omay, T., Yildirim, D. (2014), Nonlinearity and Smooth Breaks in Unit Root Testing. Econometrics Letters, 1(1): 2-9;

[20] Omay, T. (2015), Fractional Frequency Flexible Fourier Form to Approximate Smooth Breaks in Unit Root Testing. Economics Letters, 134(C): 123-126;

[21] Omay, T., Emirmahmutoglu, F., Hasanov, M. (2018), Structural Break, Nonlinearity and Asymmetry: a Re-examination of PPP Proposition. Applied Economics, 50(12): 1289-1308;

[22] Perron, P. (1989), The Great Crash, the Oil Price Shock, and the Unit Root Hypothesis. Econometrica, 57(6): 1361-1401;

[23] Phelps, E. S. (1967), Phillips Curves, Expectations of Inflation and Optimal Unemployment over Time. Economica, New Series, 34(135): 254-281;

[24] Phelps, E.S. (1994), Structural Slumps: The Modern Equilibrium Theory of Unemployment, Interest, and Assets; Cambridge: Harvard University Press;

[25] Riddell, W.C. (2018), The Labor Market in Canada, 2000-2016. IZA World of Labor, Available at: https://wol.iza.org/articles/the-labor-market-in-Canada (Accessed 15 May 2020);

[26] Shahbaz, M., Omay, T., Roubaud, D. (2019), Sharp and Smooth Breaks in Unit Root Testing of Renewable Energy Consumption: The Way Forward. The Journal of Energy and Development, 44(1): 5-39;

[27] Sollis, R. (2004), Asymmetric Adjustment and Smooth Transitions: a Combination of Some Unit Root Tests. Journal of Time Series Analysis, 25(3): 409-417. 